\title{
Abuse: An integrated and coordinated health sector response is needed
}

\author{
WE Thurston PhD
}

I $\mathrm{n}$ this issue, Drs Ilnyckyj and Bernstein (pages 801-805) conclude that Canadian gastroenterologists should be routinely asking patients about sexual and physical abuse when taking a history. The results of their survey suggest that, on average, $C$ anadian gastroenterologists understand that a history of abuse is relevant to patient management, but only about half of the respondents to their survey include abuse history in their interviews. The reasons for not asking included time constraints, personal discomfort and lack of resources for referral. They conclude that "G astroenterologists need to find a resolution to their barriers to abuse inquiry".

Ilnyckyj and Bernstein are among a growing number of health care workers calling for an increased response to the problem of abuse. I applaud their effort, and concur with their recommendation that gastroenterologists take up the challenge of routine screening for abuse.

A coordinated and integrated response would involve responding in terms of clinical practice, diagnosis and treatment of patients with many health conditions. It would also require clinical and health policy research that contributes to the understanding of the impact of abuse on heath and the role of the health sector in prevention. It should also promote advocacy for a society that does not create, condone or otherwise support violence. Programs that encourage gastroenterologists and other health providers to deal with personal experiences of sexual and physical abuse would also be beneficial.

Considerable work in promoting a health sector response has been done in the past two decades. In 1989, the FederalProvincial Advisory Committee on Institutional and $M$ edical $C$ are Services requested that guidelines be developed on health care related to abuse, assault, neglect and family violence (1). In this report, the identification of abuse and the referral to appropriate resources are stated as "basic to all [health] programs" (page 4). These guidelines were widely circulated, and regional consultations were held with educators and associations of health professionals across the country. 0 ther policy work has also been undertaken; for instance, the Canadian Psychiatric A ssociation approved guidelines for the universal screening of all psychosocial and psychiatric patients $(2,3)$ and the $M$ arch of Dimes funded the $\mathrm{N}$ ational Preceptorship Program (4). Professional associations have developed guidelines (eg, C anadian N urses A ssociation) $(5,6)$. In the U nited States, bodies such as the Joint Commission on A ccreditation of $\mathrm{H}$ ealthcare Organizations (7) recommended policies for emergency departments, and the A merican Medical A ssociation (8) established the $\mathrm{N}$ ational Coalition of Physicians A gainst Family Violence. For many years, $\mathrm{H}$ ealth $\mathrm{C}$ anada has coordinated intergovernmental violence prevention initiatives and the electronic information database of the $\mathrm{N}$ ational Clearinghouse on Family Violence.

O ne lesson from the IInyckyj and Bernstein paper is that while many health professionals recognize the need for screening for sexual and physical abuse histories, action is less frequent. The negative impact of sexual and physical abuse on the health of individuals and their families is well documented, and many undergraduate and graduate medical curricula now include courses on violence prevention. A ccording to IInyckyj and Bernstein, this information seems to have reached gastroenterologists. D espite the policy work and widespread knowledge of the significance of the problem, implementation of the protocols for screening for a history of violence is not common, often not routine, and may be dropped once started (9-12). The body of research on the screening process has grown substantially, yet continues to be insufficient (10). The results of the IInyckyj and Bernstein study support my own view that system-level variables that affect implementation and maintenance of screening programs (eg, factors affecting the time

D epartment of $\mathrm{C}$ ommunity $\mathrm{H}$ ealth Sciences, F aculty of M edicine, Faculties of $\mathrm{N}$ ursing and K inesiology and Institute for $\mathrm{G}$ ender Research, U niversity of $C$ algary, C algary, A lberta

C orrespondence: Dr WE T hurston, Department of Community $\mathrm{H}$ ealth Sciences, Faculty of $\mathrm{M}$ edicine, $\mathrm{U}$ niversity of $\mathrm{C}$ algary,

3330 H ospital D rive N orthwest, C algary, A lberta T 2N 4N 1. Telephone 403-220-6940, fax 403-270-7307, e-mail thurston@ucalgary.ca 
available to take histories, and lack of intersectoral collaboration) need greater attention. We need to look at the characteristics of the setting (13) and social context (14), and variables such as gender and victimization in order to understand how to improve uptake and maintenance of screening programs.

A coordinated and integrated response from the health sector would be beneficial, by taking some of the focus off the performance of individual practitioners. Professionals would be supported in their work symbolically and practically. A $n$ integrated response would mean close collaboration with those services outside of the health sector that have developed considerable expertise. Ilnyckyj and

\section{REFERENCES}

1. Health and W elfare $C$ anada. G uidelines for Establishing Standards: $\mathrm{H}$ ealth $\mathrm{C}$ are Related to A buse, A ssault, $\mathrm{N}$ eglect and Family Violence. O ttawa: $\mathrm{H}$ ealth and W elfare C anada, 1989.

2. Bishop J, Patterson PG R. G uidelines for the evaluation and management of family violence. C an J Psychiatry 1992;37:458-71.

3. Saunders DG , H amberger LK, H ovey M I Indicators of woman abuse based on a chart review at a family practice center. A rch Fam M ed 1993;2:537-43.

4. Young A, M CFarlane J. Preventing abuse during pregnancy: A national educational model for health providers. J N urs Educ 1991;30:202-6.

5. Canadian $\mathrm{N}$ urses $\mathrm{A}$ ssociation. Family Violence - Clinical Guidelines For N urses. Canadian N urses A ssociation 1992:3-46.

6. A merican A cademy of Pediatrics $\mathrm{C}$ ommittee on $\mathrm{C}$ hild $\mathrm{A}$ buse and $\mathrm{N}$ eglect. The role of the pediatrician in recognizing and intervening on behalf of abused women. Pediatrics 1998:101:1091-2.

7. M CLoughlin E, Lee $D$, Letellier $P$, Salber $P$. Emergency department response to domestic violence-C alifornia, 1992. M M W R - M orb M ortal W kly Rep 1993;42:617-20.

8. Taylor H G. Family violence and the community pharmacist. A m Pharm 1994;N S34:41-4.

9. Rodriguez M A, Bauer H M, M CLoughlin E, G rumbach K. Screening and intervention for intimate partner abuse practices and attitudes of primary care physicians. JA M A 1999;282:468.

10. Ramsay J, Richardson J, C arter YH, Davidson LL, Feder G. Should health professionals screen women for domestic violence? Systematic review. BMJ 2002;325:314.

11. Fanslow JL, N orton RN, Robinson EM. O ne year follow-up of an emergency department protocol for abused women. A ust N Z J Public Health 1999;23:418-20.

12. Wiist W H, M cFarlane J. The effectiveness of an abuse assessment protocol in public health prenatal clinics. A m J Public $\mathrm{H}$ ealth 1999;89:1217-21.
Bernstein stress the importance to patient outcomes and clinical practice, and that significance should not be minimalized (15-19). Screening is itself, however, a preventative and an educational intervention, conveying to the population that physical and sexual abuse have serious health consequences and can and should be discussed openly. The door may be opened for the patient to discuss abuse with the clinician or with other people in their lives. By implementing screening, professionals deliver the message that abuse is unacceptable to society (20-23). I congratulate $\mathrm{Dr}$ Ilnyckyj and $\mathrm{Dr}$ Bernstein for their contributions to understanding what can be done by gastroenterologists in this regard.

13. Dienemann J, Trautman D, Shahan JB, et al. Developing a domestic violence program in an inner-city academic health center emergency department: the first 3 years. J Emerg $\mathrm{N}$ urs 1999;25:110-5.

14. H eise $L L$, Raikes A, W atts $C H$, Zwi A B. Violence against women: A neglected public health issue in less developed countries. Soc Sci M ed 1994;39:1165-79.

15. G erbert $B, C$ aspers $N$, Bronstone $A, M$ oe J, A bercrombie $P$. A qualitative analysis of how physicians with expertise in domestic violence approach the identification of victims. A nn Intern M ed 1999;131:578.

16. Gerbert B, Caspers N, M illiken N, Berlin M, Bronstone A, M oe J. Interventions that help victims of domestic violence. $A$ qualitative analysis of physicians' experiences. J Fam Pract 2000;49:889-95

17. Thompson RS, Krugman R. Screening mothers for intimate partner abuse at well-baby care visits: the right thing to do. JA MA 2001;285:1628-30.

18. Thompson RS, M eyer BA, Smith-DiJulio K, et al. A training program to improve domestic violence identification and management in primary care: Preliminary results. Violence Vict 1998;13:395-410.

19. Rodriguez M A, Sheldon W R, Bauer H M, Perez-Stable EJ. The factors associated with disclosure of intimate partner abuse to clinicians. J Fam Pract 2001;50:338-44.

20. Thomas $P$, Lowitt NR. Clinical problem-solving. A traumatic experience. N Engl J M ed 1995;333:307-10.

21. A lpert EJ. Violence in intimate relationships and the practicing internist: $\mathrm{N}$ ew "disease" or new agenda? A nn Intern M ed 1995;123:774-81.

22. Helton A S. Protocol of C are for the Battered Woman. N ew York: M arch of Dimes Birth Defects Foundation, 1987

23. Randall T. Domestic violence intervention calls for more than treating injuries. JA M A 1990;264:939-40. 


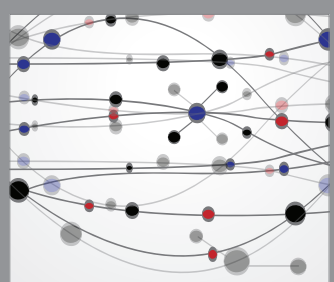

The Scientific World Journal
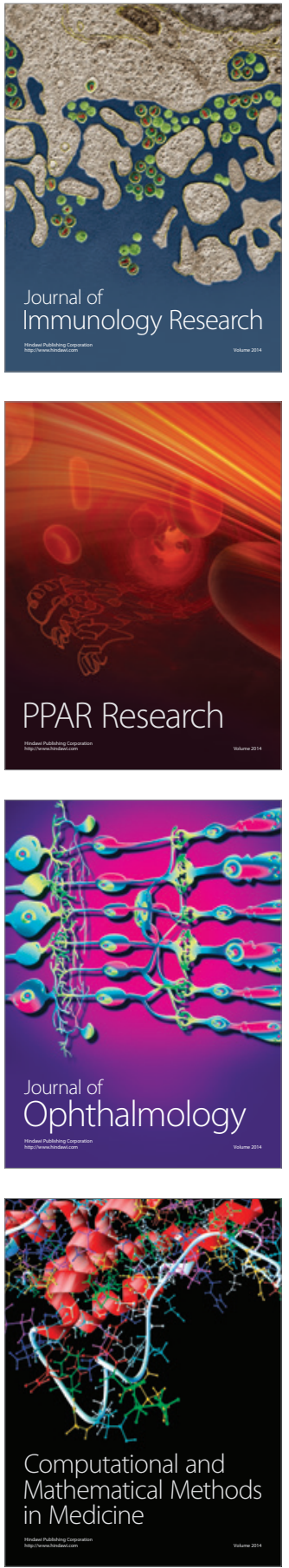

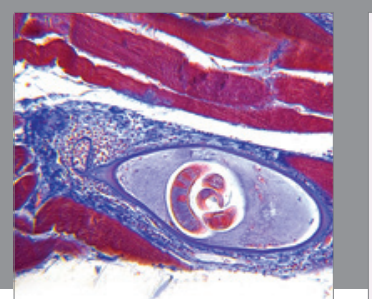

Gastroenterology Research and Practice

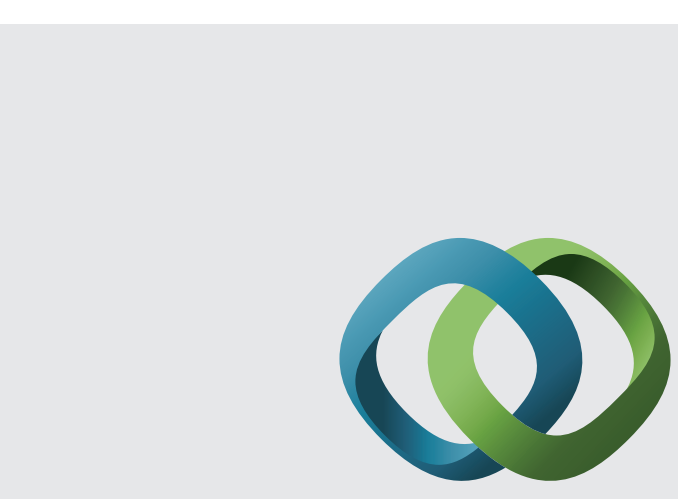

\section{Hindawi}

Submit your manuscripts at

http://www.hindawi.com
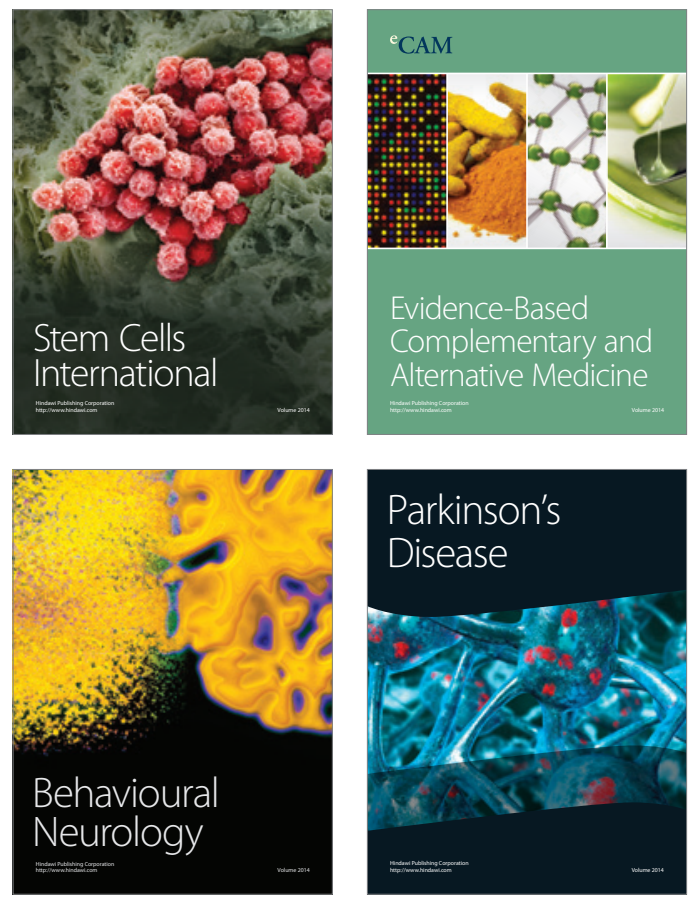
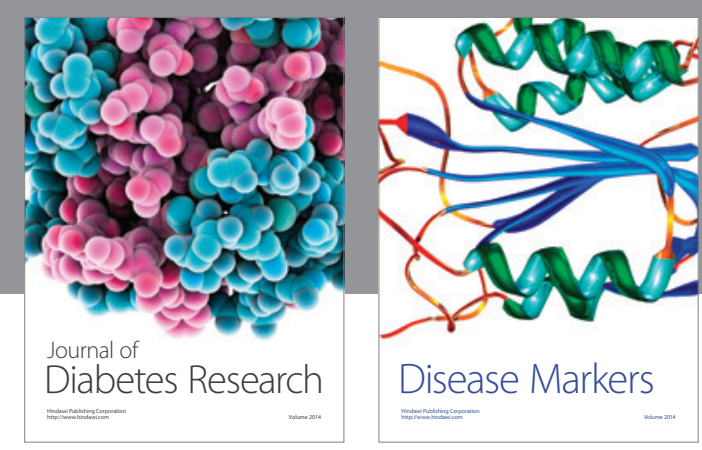

Disease Markers
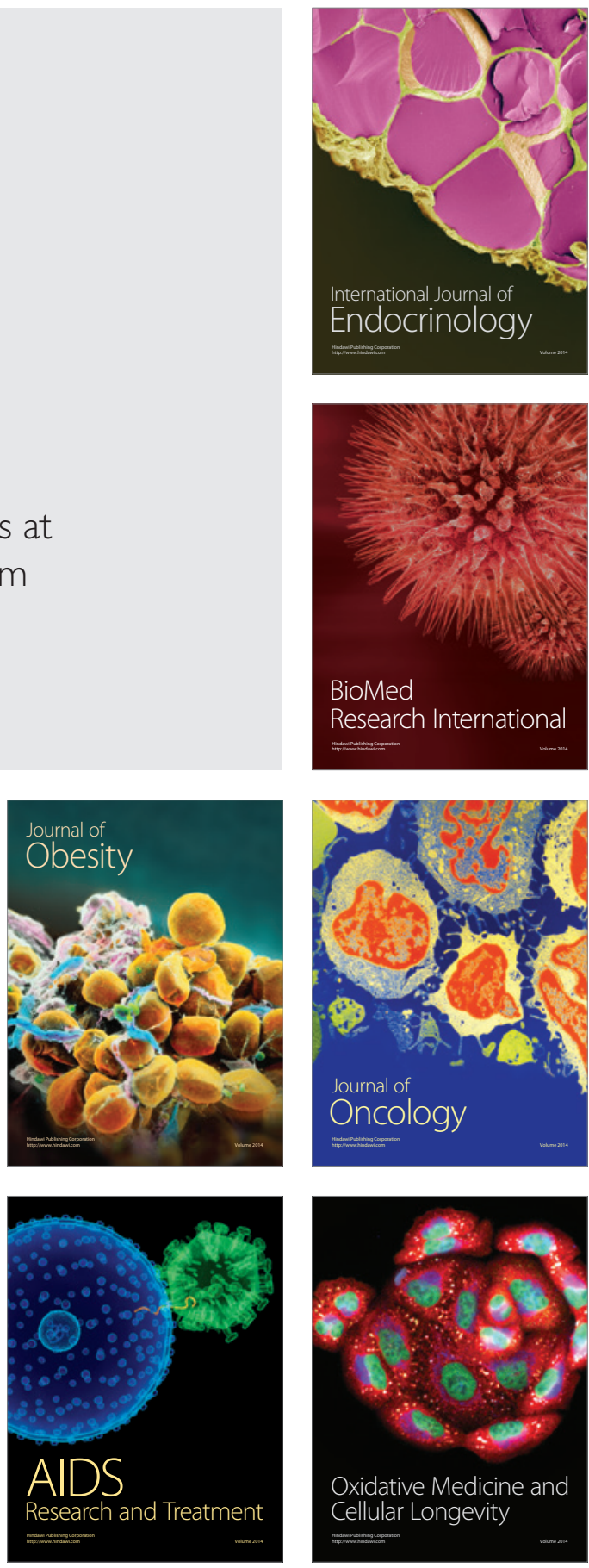